\title{
A interferência da modulação da voz do docente na aprendizagem de universitários cegos
}

The interference of teacher voice modulation in the learning of blind university students

La interferencia de la modulación de la voz del docente en el aprendizaje de universitarios ciegos

\section{Carolina Conceição Prado}

Professora no Centro Universitário do Distrito Federal - UDF, Brasília, Distrito Federal, Brasil. carolcprado@gmail.com

ORCID - https://orcid.org/0000-0003-4247-0695

\section{Teresa Ferreira Feitosa}

Professora no Centro Universitário do Distrito Federal - UDF, Brasília, Distrito Federal, Brasil. teresa_ffeitosa@hotmail.com

ORCID - https://orcid.org/0000-0003-4321-8029

Recebido em 19 de julho 2019

Aprovado em 4 de outubro de 2019

Publicado em 9 de março de 2020

\section{RESUMO}

O docente utiliza a fala como uma forma de transmissão do conhecimento aos seus alunos, em especial aos alunos cegos, ajudando-os a superar suas limitações. Este trabalho analisou, sob o ponto de vista de pessoas com deficiência visual, como a modulação da voz do docente interfere no aprendizado, interesse e motivação ao longo do curso de graduação. Foi realizada uma pesquisa qualitativa, utilizando entrevistas semiestruturadas, com 11 estudantes cegos de ambos os sexos regularmente matriculados em diversas áreas do conhecimento, no ensino superior. Os resultados mostraram que os cegos percebem na modulação da voz do docente, a empatia desse com relação a eles, e quando o docente sabe, ou não, como proceder de forma adequada aos alunos com deficiência visual. Há necessidade de materiais de ensino adaptados, de mobilidade adequada e de professores capacitados, para se melhorar o ensino para cegos. Percebeu-se que a variação no timbre, na altura e na frequência da voz do professor pode motivar ou desmotivar o aluno cego. Concluiu-se que a modulação de voz do docente serve como um intermédio entre o cego e o conhecimento consolidado, de forma eficiente.

Palavras-chave: Deficiência visual; Ensino-aprendizagem; Ensino superior.

\section{ABSTRACT}

The teacher uses speech as a way of transmitting knowledge to his students, especially blind students, helping them overcome their limitations. This work analyzed, from the point of view of visually impaired people, how the modulation of the teacher's voice interferes with learning, interest and motivation throughout the undergraduate course. A qualitative research was conducted, using semi-structured interviews, in 11 blind students of both sexes regularly enrolled in various areas of knowledge in higher education. The results 
http://dx.doi.org/10.5902/1984686X39149

showed that the blind perceive in the modulation of the teacher's voice, their empathy towards them, and when the teacher knows or not, how to proceed appropriately to students with visual impairment. Adapted teaching materials, adequate mobility and trained teachers are needed to improve teaching for the blind. It was noticed that the variation in tone, pitch and frequency of the teacher's voice can motivate or demotivate the blind student. It was concluded that the teacher's voice modulation serves as an intermediate between the blind and the consolidated knowledge, efficiently.

Keywords: Visual impairment; Teaching and learning; Higher education.

\section{RESUMEN}

El maestro usa el habla como una forma de transmitir conocimiento a sus alumnos, especialmente a los alumnos ciegos, ayudándoles a superar sus limitaciones. Este trabajo analizó, desde el punto de vista de las personas con discapacidad visual, cómo la modulación de la voz del profesor interfiere con el aprendizaje, el interés y la motivación a lo largo del curso de pregrado. Se realizó una investigación cualitativa, utilizando entrevistas semiestructuradas, en 11 estudiantes ciegos de ambos sexos matriculados regularmente en diversas áreas de conocimiento en la educación superior. Los resultados mostraron que los ciegos perciben en la modulación de la voz del maestro, su empatía hacia ellos y, cuando el maestro sabe o no, cómo proceder adecuadamente con los estudiantes con discapacidad visual. Se necesitan materiales didácticos adaptados, movilidad adecuada y maestros capacitados para mejorar la enseñanza para los ciegos. Se notó que la variación en el tono, tono y frecuencia de la voz del maestro puede motivar o desmotivar al estudiante ciego. Se concluyó que la modulación de voz del maestro sirve como intermediario entre el ciego y el conocimiento consolidado, de manera eficiente.

Palabras clave: Deficiencia visual; Enseñanza y el aprendizaje; Enseñanza superior.

\section{Introdução}

Para Amaral (1996) deficiência refere-se a uma perda ou anormalidade de estrutura ou função, que deixa o indivíduo incapacitado ou com restrição de atividades em decorrência do problema. Segundo a Organização Mundial de Saúde - OMS, desde 1972 deficiência visual é a condição de falta de percepção visual, devido a fatores fisiológicos ou neurológicos. Várias escalas têm sido desenvolvidas para descrever a extensão da perda de visão e definir a deficiência. Deficiência visual total é a completa falta de percepção visual de forma e luz (GIL, 2000).

Em 1979, a OMS comunicou que em 1975 havia 28 milhões de pessoas cegas no mundo e o triplo de pessoas com baixa visão. Essas estimativas foram revistas em $1990 \mathrm{e}$ projetadas para o futuro: em 2010 seriam 58 milhões e em 2020, 75 milhões de pessoas com deficiência visual no mundo (IAPB, 2014). Atualmente, sabe-se que são 285 milhões de pessoas no mundo vivendo com baixa visão ou cegueira. Destes, 39 milhões são cegas e 246 milhões têm moderada ou grave deficiência visual. No Brasil, existem mais de 6,5 
http://dx.doi.org/10.5902/1984686X39149

milhões de pessoas com deficiência visual, de acordo com os dados do Censo 2010, do Instituto Brasileiro de Geografia e Estatística - IBGE (OLIVEIRA, 2012).

Com o advento da tecnologia do século XXI, informações visuais chamativas e sofisticadas têm sido empregadas nos canais de comunicação e, assim, alcançado as redes de ensino pelo mundo. Essas tecnologias, na educação, têm incentivado a criação de didáticas diferenciadas e mais motivacionais, permeadas de símbolos gráficos, imagens, letras e números, por exemplo. Não obstante, ao se tratar de pessoas com deficiência visual, essas informações visuais acabam não sendo adequadas e até podem se tornar excludentes, exigindo que novas formas de comunicação, táteis ou auditivas, sejam aperfeiçoadas e dinamizadas, para que se alcance esse público satisfatoriamente (SÁ; CAMPOS; SILVA, 2007).

No Brasil, a preocupação com material adequado e o acesso à informação, para pessoas com deficiência visual, já foi pensado, discutido e concretizado na forma da Lei das Diretrizes e Bases da Educação Nacional. O art. 59 e inciso I, da LDB 9394/96, diz o seguinte:

Os sistemas de ensino assegurarão aos educandos com deficiência, transtornos globais do desenvolvimento e altas habilidades ou superlotação: currículos, métodos, técnicas, recursos educativos e organização específicos, para atender às suas necessidades (BRASIL. 1996. p. 08).

A lei se faz necessária, para que haja acessibilidade à educação, de pessoas com deficiência visual, e também, locais que proporcionem aos educandos a superação dos seus limites, que os estimulem e os motivem, os desenvolvam a iniciativa e a autonomia, e que diminuam os fatores que os levam à reprovação ou à desistência (SÁ; CAMPOS; SILVA, 2007).

A Convenção sobre os Direitos das Pessoas com Deficiência, adotada pela Organização das Nações Unidas - ONU em 2006, é um marco na busca da equidade e justiça sociais, para esse público, pois reconheceu a deficiência como um conceito em evolução que resulta da interação entre pessoas com deficiência e os empecilhos ambientais e sociais que impedem a completa e eficaz participação dessa pessoas na sociedade em igualdade de oportunidades com as demais pessoas (ONU, 2006). Assim, as atitudes dos atores envolvidos no processo de ensino-aprendizagem podem facilitar ou não, a educação de alunos com deficiência.

Pensando a respeito das necessidades da pessoa com deficiência visual e dos fatores que contribuem para sua aprendizagem, a pesquisa base deste trabalho partiu do 
importante veículo de informação que conecta o educando com o mundo: a linguagem. Segundo Vygotsky (1997a), importante teórico que desenvolveu uma gama de estudos e estratégias de educação para pessoas com deficiência, é a linguagem que ajudará o aluno com deficiência visual a superar as limitações produzidas pela impossibilidade de enxergar, por meio da compensação social.

A linguagem é considerada uma função mental superior que se refere à competência de aquisição e utilização de sistemas complexos de comunicação, para transmitir e compartilhar informações. Só pode ser adquirida por meio da interação social. É por intermédio dela e de outro indivíduo que a pessoa com deficiência visual terá acesso à realidade, por meio da significação, a partir da intersubjetividade (GÓES, 1993; 1995). Ademais, é pela linguagem e pelas relações sociais que serão possíveis o processo de assimilação do conhecimento (VYGOSTSKY, 1997b).

Na neurociência, acredita-se que $80 \%$ de nosso conhecimento se baseiam na visão. A visão se sobressai na hierarquia dos sentidos, por permitir a percepção das formas, tamanhos, cores e por ser um elo entre os outros sentidos, já que proporciona a associação da visão com os outros sentidos. Mas, na ausência da visão, os outros sentidos acabam sendo mais estimulados, porque as pessoas cegas recorrem a eles com mais frequência e, por isso, apresentam um mapeamento cortical diferenciado. Dentre os sentidos mais estimulados pelas pessoas com deficiência visual, encontra-se a audição, que é a capacidade de perceber os sons que são capturados pelos receptores auditivos, encontrados na orelha, que transformam os impulsos eletromagnéticos em impulsos nervosos, que são percebidos e interpretados no córtex cerebral, dando ao indivíduo informações acerca do espaço, da fala e da mensagem que the são transmitidas (LENT, 2003).

A partir da escuta da fala do emissor no processo de comunicação, a pessoa com deficiência visual, que possui seu córtex auditivo bem desenvolvido, devido à plasticidade cerebral, consegue perceber informações que vão além das ideias, pensamentos e conceitos expressos. A pessoa com deficiência visual percebe variações no ritmo (pausa, cadência e pontuação), na velocidade (lenta ou rápida), no timbre (grave ou agudo), na tonalidade (forte ou fraco) e na intensidade (volume baixo ou alto) da fala do emissor. Consegue sentir impressões de afeto, alegria ou dor, segurança ou insegurança, estado de tensão ou de relaxamento, prazer ou desprazer, timidez ou impavidez; e até delinear a 
http://dx.doi.org/10.5902/1984686X39149

personalidade do emissor, dentre outras possibilidades perceptivas (DEL PRETTE; DEL PRETTE, 2005).

É tão impressionante essa sensibilidade e empatia auditiva, das pessoas com deficiência visual, que a maioria os videntes capazes de perceber sons não conseguem delas chegar perto, em níveis qualitativos, por falta de treino, pois recorrem mais à visão para as captar, nas expressões do corpo e da face, do que na qualidade da voz.

A maneira como a voz de um educador é articulada pode ser capaz de interferir na qualidade da mensagem a ser transmitida e no alcance dos seus reais objetivos, em alunos com ou sem deficiência visual. Pode-se, por exemplo, transmitir a impressão de ameaça, de falta de educação, de indiferença e de diversas outras emoções, de mensagens que acabam, sem que o educador perceba, interferindo no processo de ensino-aprendizagem em sala de aula, sobretudo no caso de alunos que necessitam de educação especial.

O professor tem um importante papel para o aprendizado de qualquer aluno, inclusive o aluno com deficiência visual. E quando este percebe que tem daquele, a atenção, o afeto, o incentivo e a segurança, por sua voz, se sente motivado a responder às exigências do professor e da disciplina. Segundo Skinner (2003), se para o aluno que tem limitações visuais, os determinantes reforçadores de seu comportamento são a atenção, o elogio e o incentivo pelas palavras, o professor pode fazer com que a probabilidade do comportamento de estudar e frequentar as aulas aumente, por meio do condicionamento operante, mais especificamente, pelo reforço positivo, que é reforçador pelo aumento da probabilidade da emissão de um determinado comportamento positivo, por comportar adição de algo, nesse caso, palavras positivas e entusiasmo na voz do professor.

Entretanto, pode ocorrer a diminuição do comportamento, quando não houver reforçamento, ou seja, extinção do comportamento proativo, quando esse não produzir mais as consequências reforçadoras de antes. Assim, por não haver atenção ou incentivo, estímulos determinantes do comportamento desejado, pode-se ter uma diminuição do interesse pelas aulas, consequente, inassiduidade e até mesmo evasão. Ademais, em casos mais graves, de humilhação, grosseria, "bullying", não aceitação ou preconceito, o professor pode se tornar estímulo aversivo, e o aluno deixará de responder às expectativas do professor, porque nesse caso houve punição positiva (TODOROV; HANNA, 2010).

Skinner reconhece a importância do professor em sala de aula, visto que a pessoa que é ensinada aprende muito mais rápido do que quem não é. Compete ao professor achar as determinantes que estimulem seus alunos, arranjar contingências de reforço e fornecer 
situações de modo que o educando passe a emitir e a manter comportamentos que se pretende alcançar por meio da Modelagem do Comportamento (SKINNER, 1972).

Com o conhecimento da importância da voz e do que se imprime por meio dela, pelo seu modo de transmissão, o professor pode tomar consciência e até mesmo usar isso a seu favor e conseguir ser coerente nas suas intenções e, na fala, manipulá-la e ser um mediador eficaz. Seguindo as teorias de Skinner, por meio da fala pode-se transmitir entusiasmo, alegria, incentivo, elogios, e reforçar o comportamento que se deseja do aluno, como já foi dito. Ademais, de acordo com Vygotsky (1998), valorizar as experiências auditivas, além das demais, na pessoa com deficiência, é tão importante quanto "proporcionar intervenções que favoreçam a formação de conceitos por meio dos processos de significação, promovendo assim, o desenvolvimento das funções psicológicas superiores" (VYGOTSKY, 1998 p. 56).

A pesquisa em questão buscou, com base nos teóricos Skinner e Vygotsky, contribuir para a capacitação do educador que leciona para alunos com deficiência visual, dando-lhe informações acerca da importância da voz e do que ela pode transmitir ao aluno sensível às propriedades do som. Destarte, teve por objetivo investigar os aspectos inerentes à fala do educador, sob a perspectiva de pessoas com deficiência visual, como e por que as representações feitas a partir da percepção da fala do emissor podem interferir na aprendizagem, assiduidade, motivação e interesse do aluno nas aulas e na disciplina lecionada. Foram feitas entrevistas semiestruturadas com alunos com deficiência visual regularmente matriculados em instituições de ensino superior do Distrito Federal, sobre suas experiências auditivas advindas da fala de seus educadores e a interferência dessas experiências na aprendizagem e na motivação.

A fim de contribuir para a reflexão da aplicação de técnicas de abordagem comportamental e cognitiva, buscando fornecer apoio aos professores de instituições superiores que pretendem atingir seus objetivos com eficácia e tornarem-se mediadores mais afetivos, capaz de estimular seus alunos com deficiência visual e de os motivar a manterem-se afinco nos estudos, além de os ajudar a superar seus limites. Por oportuno, frisa-se que se buscou identificar aspectos positivos e negativos na fala dos educadores, que podem interferir no aprendizado de pessoas com deficiência visual, para a melhoria da educação de pessoas com deficiência visual no ensino superior do Distrito Federal. 
http://dx.doi.org/10.5902/1984686X39149

\section{Metodologia}

Foi realizada uma pesquisa qualitativa, pois a investigação requereu uma ferramenta que trabalhasse as percepções das pessoas com deficiência visual, suas opiniões e as representações que elas fazem a partir das propriedades da fala de um emissor, ou melhor, de um educador, na sua atuação em sala de sala.

Participaram da pesquisa 11 indivíduos cegos, que não tinham relações de parentesco entre si. Todos tinham o diagnóstico de deficiência visual total, com classificação de ausência de percepção de luz e forma, seja adquirida (neste caso, posterior aos 05 anos de idade) ou congênita. O grupo era heterogêneo, em termos de área de conhecimento, e todos estavam academicamente ativos e ingressos no ensino superior. Além desses, outras duas pessoas, da Biblioteca Braile Dorina Nowill, participaram na forma de testemunhas, para lerem o Termo de Consentimento Livre e Esclarecido aos voluntários da pesquisa, por questões legais.

O instrumento utilizado para viabilizar a coleta de dados se baseou em entrevistas individuais, com 12 perguntas semiestruturadas, previamente elaboradas por meio de um roteiro, que teve como tema central a comunicação entre professor e aluno, no ambiente de sala de aula. Para deixá-los à vontade, para verbalizar e expressar frente ao tema focalizado, a entrevista durou cerca de 40 minutos, com cada participante. Os dados foram gravados, para garantir a maior preservação possível, dos discursos selecionados, e, em seguida, foram transcritos. As atitudes dos entrevistados e detalhes importantes das entrevistas, não captadas pelos gravadores, foram anotadas.

A análise dos dados seguiu um critério sistemático, que levou em consideração três pontos importantes, interligados entre si: apreensão dos significados da fala do sujeito; o contexto ou realidade sob o estudo; e as abordagens conceituais. Esse processo tratou de definir os núcleos de interesse do pesquisador que teriam vinculação direta aos pressupostos teóricos (abordagem conceitual) e contatos prévios com a realidade sob estudo, ou seja, existe uma direção, ainda que não de forma totalmente declarada, para o conteúdo que vai seria obtido nas entrevistas, ao mesmo tempo em que há garantia de adequação do roteiro ao universo de vida dos sujeitos. 


\section{Resultados e Discussão}

O presente trabalho, em concordância com os seus objetivos, relata, por meio da análise de dados, as entrevistas realizadas com estudantes com deficiência visual que estão inseridos no ensino superior. Os resultados obtidos mostram que os participantes possuem idade média de 39,4 anos e que estudam em seis instituições de ensino superior do Distrito Federal, sendo uma pública, com o campus no Plano Piloto, e as demais privadas, distribuídas pelas cidades satélites do Distrito Federal. Os cursos de graduação dos participantes são: administração, direito, jornalismo, letras em espanhol, psicologia, publicidade e propaganda, recursos humanos, e serviço social. Ao serem questionados sobre a adequação do curso às suas necessidades especiais, $82 \%$ afirmam que não consideram o curso adequado devido à falta de professores capacitados, material didático acessível, mobilidade adequada dentro da instituição e profissionais adequados para ler e interpretar provas e materiais didáticos.

Com base nos resultados quanto à adequação dos cursos de graduação, nota-se que as instituições de ensino superior estão negligenciando os direitos e, consequentemente, prejudicando a acessibilidade e a inclusão social que estão previstas pela Lei de Diretrizes e Bases da Educação Nacional, conforme art. 59 e inciso I, da LDB 9394/96 (BRASIL, 1996).

No que diz respeito à importância do uso da voz na transmissão do conhecimento, foi unânime a afirmação de que a fala é essencial na vida da pessoa com deficiência visual. Dos participantes da pesquisa, $73 \%$ afirmam que existem diferenças na modulação de voz do docente que interferem na aprendizagem, sendo que $50 \%$ deles afirmaram que notam pela expressividade da fala e pelo timbre utilizado, se o docente está interessado em ensiná-los e sanar suas dúvidas, ou não. Além da percepção do interesse do educador, foi relatado que a mudança de tonalidade da voz, durante a explicação do conteúdo, influencia na segurança que o aluno tem com relação ao que está sendo ministrado, e na empatia que o aluno cria com o docente (Quadro 1). 
http://dx.doi.org/10.5902/1984686X39149

Quadro 1: Trechos das entrevistas com os participantes, sobre a importância da modulação de voz na transmissão do conhecimento.

\begin{tabular}{|c|c|}
\hline Eixo na entrevista & Relato de experiência \\
\hline \multirow{6}{*}{$\begin{array}{l}\text { Importância da modulação de voz na } \\
\text { transmissão do conhecimento }\end{array}$} & "[...] A voz é a nossa forma de enxergar a vida [...]" \\
\hline & $\begin{array}{l}\text { "[...] Fundamental porque a forma como a voz é proferida dá a } \\
\text { primeira impressão que o deficiente visual tem da pessoa [...]" }\end{array}$ \\
\hline & "[...] Importante, sem ela é quase impossível [...]" \\
\hline & "[...] Auxiliam, de acordo com a entonação [...]" \\
\hline & $\begin{array}{l}\text { "[...] Para o Deficiente Visual, a expressão ocorre por meio da } \\
\text { entonação [...]" }\end{array}$ \\
\hline & $\begin{array}{l}\text { "[...] Posso ficar empolgado ou completamente desmotivado } \\
\text { apenas observando o volume e a velocidade da voz de alguém } \\
{[\ldots . .]}\end{array}$ \\
\hline
\end{tabular}

Fonte: Autores, 2019.

Segundo Del Prette e Del Prette (2005), como já dito, a pessoa com deficiência visual percebe variações no ritmo, na velocidade, no timbre, na tonalidade e na intensidade da fala do emissor e consegue sentir impressões de afeto, alegria ou dor, segurança ou insegurança, estado de tensão ou relaxamento, prazer ou desprazer, timidez, sua personalidade, dentre outras impressões possíveis. É surpreendente o desenvolvimento auditivo advindo das pessoas com deficiência visual, principalmente quando se compara a sensibilidade auditiva dos cegos com a dos videntes, tendo em vista que estes desenvolvem muito mais a sua visão para fazer tais associações.

Ao serem questionados sobre situações do cotidiano, a respeito da fala do docente que interferem de forma positiva no aprendizado, 36\% dos entrevistados descreveram que se o educador expressar-se de forma clara, firme e segura, já é suficiente para que o aprendizado seja motivado. Para outros $36 \%$ dos entrevistados, a demonstração de preocupação em procurar outras alternativas que facilitem o entendimento do estudante cego é importante para o aprendizado. Como influência negativa, 45\% dos participantes listaram que muitos professores não compreendem as limitações dos discentes e não sabem como transmitir conhecimentos de forma adaptada, à realidade do aluno cego. Outros $27 \%$ relataram que a falta de descrição do que está sendo exposto visualmente intervém negativamente em seus aprendizados.

No que tange às diferenças na modulação de voz do educador, $73 \%$ dos entrevistados afirmaram que falar com clareza, expressividade, empatia e segurança motiva e facilita 0 aprendizado. $18 \%$ deles citaram que a animação do professor em sala, buscando criar um 
http://dx.doi.org/10.5902/1984686X39149

vínculo com o aluno, mesmo que seja apenas o cumprimentando, funciona como motivação. Em contrapartida, $55 \%$ dos participantes alegaram que a falta de expressividade, o baixo tom e a falta de segurança ao falar, provocando oscilações na frequência e até mesmo no timbre da voz, são pontos desmotivadores. Além disso, 36\% dos participantes descreveram que a arrogância, a ironia e a irritação, usadas ou demostradas pelos docentes quando precisam reexplicar algo, não são só desmotivadoras, como desgastantes, e que elas são perceptíveis pela voz, uma vez que, normalmente, há aumento da tonalidade, da altura e da frequência do som Dentre os entrevistados, $9 \%$ relataram que apesar de cada professor possuir um jeito único de falar, nenhum jeito desmotiva a vontade de aprender do aluno. O Quadro 2 apresenta trechos das falas dos participantes sobre o impacto negativo que a forma como o docente fala (modula sua voz) causa no aprendizado de alunos com deficiência visual.

Quadro 2: Trechos das entrevistas com os participantes sobre o impacto negativo que a forma como o docente fala causa no aprendizado de alunos com deficiência visual.

\begin{tabular}{|c|c|}
\hline Eixo na entrevista & Relato de experiência \\
\hline $\begin{array}{l}\text { Situações do cotidiano que mostram a } \\
\text { influência negativa da forma como o } \\
\text { docente fala }\end{array}$ & $\begin{array}{l}\text { "[...] Teve um professor no meu } 10 \text { semestre que ficava bem } \\
\text { confuso em descrever o que estava no quadro. Sua voz era } \\
\text { tremula e não passava segurança. Ele falava que não sabia lidar } \\
\text { com o deficiente visual e que achava dif́cil. Ele não sabia como } \\
\text { transmitir para mim o conhecimento [...]" } \\
\text { "[...] Quando o professor fala muito rápido, é frustrante, pois fica } \\
\text { difícil assimilar o que está dizendo [...]" } \\
\text { "[...] Uma vez fui apresentar um trabalho e o professor foi } \\
\text { arrogante, só pontuou as coisas negativas. Seu tom de voz era } \\
\text { mais alto do que o normal e falava rápido, como se quisesse } \\
\text { acabar logo. Ele não ressaltou o meu esforço e força de vontade } \\
\text { em fazer o trabalho. Isso desmotivou bastante [...]" } \\
\text { "[...] Tive uma professora que falava tão devagar quando estava se } \\
\text { dirigindo a mim que me constrangia. Sou deficiente visual, não } \\
\text { cognitivo. Era indigesto. A turma sempre conversava muito nessa } \\
\text { hora, pois ninguém tinha paciência para ouvir [...] } \\
\text { "[...] A professora me disse que caiu de paraquedas na sala. Ela } \\
\text { disse que não sabia como lidar com um deficiente visual. Sua voz } \\
\text { era muito baixa e não prendia a atenção dos alunos [...]" } \\
\text { "[...] O professor usava o mesmo tom de voz durante a aula toda. } \\
\text { Não tinha como entender o que era mais importante e o que não } \\
\text { era. Provocava cansaço e sonolência [...]" }\end{array}$ \\
\hline
\end{tabular}

Fonte: Autores, 2019.

Percebe-se que a forma como o docente lida com as necessidades do estudante com deficiência visual pode interferir tanto positivamente, quanto negativamente no 
aprendizado. Segundo Vygotsky (1998), isso ocorre devido a capacidade cognitiva do estudante resultar das experiências vividas por ele. No decorrer da pesquisa, notou-se também que a estruturação na voz do docente é capaz de interferir na maneira como a informação emitida é captada pelo aluno com deficiência visual. Skinner (2003) e Todorov e Hanna (2010) asseguram que a forma como o professor utiliza os determinantes reforçadores de alunos com limitações visuais funciona como um gatilho motivador ou desmotivador.

Os resultados mostraram que $64 \%$ dos participantes listaram que materiais didáticos adequados e acessíveis, bem como a mobilidade adequada, interferem no aprendizado de estudantes de ensino superior com deficiência visual. Outra importante característica listada pelos entrevistados, que interfere no aprendizado, foi a preocupação dos docentes em procurar metodologias de ensino que se adaptem à realidade do aluno com deficiência visual. No que diz respeito aos métodos que facilitem o aprendizado da pessoa com deficiência visual em uma aula extremamente visual, $82 \%$ afirmaram que apenas a descrição e a leitura do que está sendo exposto ou projetado é o suficiente para maior absorção de conhecimento. Outro ponto importante, citado pela maioria, foi o uso de materiais didáticos táteis, para que os alunos cegos possam fazer uma associação com o visual. Os entrevistados emitiram suas opiniões pessoais a respeito da importância de uma melhor utilização da fala pelos educadores, visando aprimorar o aprendizado e a compreensão dos alunos com deficiência visual em sala de aula, como pode ser observado no Quadro 3.

Quadro 3: Trechos das entrevistas com os participantes sobre a opinião dos entrevistados com relação ao que o educador deve saber sobre a entonação de sua voz na transmissão do conhecimento

\begin{tabular}{|c|c|}
\hline Eixo na entrevista & Relato de experiência \\
\hline $\begin{array}{l}\text { Opiniões pessoais a respeito da } \\
\text { importância de uma melhor utilização } \\
\text { da fala pelos educadores }\end{array}$ & $\begin{array}{l}\text { "[...] Saber que a forma como se fala pode levantar e diminuir a } \\
\text { pessoa. Que ela pode aumentar autoestima como também abaixar } \\
\text { mais ainda. Saber o poder da palavra [...]" } \\
\text { "[...] Deveriam saber que a voz é tudo para a gente. Deveriam } \\
\text { saber que a voz é a primeira ferramenta de contato com a pessoa, } \\
\text { porque visualmente a gente não está em contato com nada [...]" } \\
\text { "[...] Procurar entender as diferenças e deixar o preconceito de } \\
\text { lado [...]" } \\
\text { "[...] Pela voz consigo identificar o professor e os conteúdos } \\
\text { trabalhados por ele [...]" } \\
\text { "[...] Posso captar o sentimento do Professor pela entonação de } \\
\text { sua voz." }\end{array}$ \\
\hline
\end{tabular}

Fonte: Autores, 2019. 
http://dx.doi.org/10.5902/1984686X39149

Como alternativas de melhoria do aprendizado, foi unânime a sugestão de materiais didáticos mais acessíveis e adaptados, além da mobilidade adequada, como piso tátil, rampas de acesso e portas com identificação em braile. 64\% dos entrevistados consideram que professores capacitados com cursos de ledor braile, inclusão e/ou oratória podem aperfeiçoar e adaptar a sua forma de lecionar, melhorando o aprendizado de alunos com deficiência visual. 18\% dos entrevistados afirmam que as instituições de ensino superior e quaisquer outras instituições que busquem estabelecer melhorias para pessoas com deficiência, devem consultar seu público com necessidades especiais, a fim de garantir uma correta adaptação estrutural e material, principalmente didática.

A Lei Federal 10.098/2000 e o Decreto Federal 5.296/2004 asseguram a acessibilidade estrutural para todos, sendo portador de deficiência ou não (BRASIL, 2000; 2004). Essa lei garante o direito de ir e vir de forma independente, certificando que qualquer bloqueio que limite ou impossibilite o acesso de pessoas com deficiência de maneira autonômica e segura, deve ser retirado. Porém, essa acessibilidade estrutural não é fornecida pelas instituições de ensino superior, dificultando assim a independência, no que diz respeito à mobilidade necessária para as pessoas com deficiência visual.

Percebe-se, também, que parte dos entrevistados cita que cursos de capacitação são alternativas que melhorariam o aprendizado. Essa falta de capacitação profissional pode ser o motivo pelo qual muitos docentes relatam dificuldades em lidar com alunos com deficiência visual e em adaptar o seu planejamento de aula quanto às necessidades do aluno cego. Segundo Barbosa (2008), em seu trabalho sobre "A importância do pensamento visual na geometria”, o professor precisa:

Selecionar, adaptar e confeccionar materiais didático-pedagógicos que
contribuam para o processo ensino-aprendizagem de todos os alunos, sejam
eles deficientes visuais ou não. A escolha deve basear-se, de um modo geral,
nos princípios de que os materiais mais adequados são aqueles que
permitem uma experiência completa ao aluno e estão compatíveis com o seu
nível de desenvolvimento (BARBOSA. 2008. p. 03).

Analisando as entrevistas, pode-se observar que apesar da diferença nas falas, quando questionados a respeito da influência positiva e negativa na fala do educador, observa-se uma predominância das opiniões dos participantes da pesquisa quanto à diferença na voz do docente que interferem na aprendizagem e quanto à necessidade do educador saber a importância de adequadamente utilizar a sua voz com discentes, principalmente os com deficiência visual. Acredita-se que isso é recomendado, pois os cegos "se tornam extremamente sensíveis aos matizes de inflexão, de volume, de cadência, 
de ressonância e das várias intensidades dos sons das falas dos outros, que passam despercebidos aos videntes" (RABÊLLO. 2003. p. 78).

\section{Considerações finais}

O processo de inclusão tem como objetivo proporcionar a todos os alunos um ensino eficaz e de qualidade que se encaixe dentro de sua realidade e necessidade especial, quando necessário. A falta de acessibilidade estrutural e material adequada e o uso de recursos extremamente visuais como principal meio de transmissão do conhecimento são uma realidade que prejudicam o aprendizado de estudantes com deficiência visual. Inserida nessa realidade, a voz aparece como a ferramenta principal e mais utilizada para a propagação do conhecimento.

A estruturação da modulação de voz surge ao longo do convívio social e torna-se um meio de identificação sensorial. A capacidade sensorial que as pessoas com deficiência visual possuem em interpretar as variações da voz, proporciona orientações de como a voz deve ser utilizada para a melhoria do ensino de alunos com deficiência visual. Como consequência disso, a voz do emissor funcionará como intermediador entre o estudante e o mundo social que o cerca.

Nesse ponto de vista, a relação entre a fala e a audição, dentro do ensinoaprendizagem, se torna o elemento fundamental para a melhoria do aprendizado e crescimento acadêmico de alunos com deficiência visual. Nesse contexto, torna-se necessária a elaboração de cursos de formação para docentes de ensino superior na área de educação especial, que busquem aprimorar, no âmbito psicológico, cognitivo e social, a educação de alunos com cegueira inseridos em cursos de graduação de instituições de ensino superior do Distrito Federal.

Através dos resultados obtidos, conclui-se que o objetivo geral desta pesquisa foi alcançado, no que se refere à investigação dos aspectos inerentes da fala do educador sob a perspectiva dos alunos com deficiência visual, e como e por que as representações que esse alunos fazem, a partir da percepção da fala do emissor, podem interferir na sua aprendizagem, assiduidade, motivação e interesse nas aulas e disciplina lecionada.

Ademais, foi possível fazer um levantamento de dados para identificar aspectos positivos e negativos na fala dos educadores que podem interferir no aprendizado de alunos com deficiência visual, além das experiências auditivas advindas da fala de seus educadores e da interferência dessa fala na aprendizagem de graduandos com deficiência 
visual. Em oportuno, é possível afirmar-se que as ideias iniciais deste estudo estão em concordância com as teorias de Skinner e Vygotsky, tendo em vista que a audição tem um papel fundamental no aprendizado do estudante cego, pois fornece a ele, junto ao tato, a possibilidade de fazer associações que facilitem o seu aprendizado.

\section{Referências}

AMARAL, Lígia Assumpção. Deficiência: Questões Conceituais e Alguns de seus Desdobramentos. Minas Gerais: Caderno de Psicologia. V.2, n 1, 1996: 3 -12. Disponível em: http://www.cadernosdepsicologia.org.br/index.php/cadernos/article/view/11/8. Acesso em 12 jul. 2019.

BARBOSA Paula Márcia. A importância do pensamento visual na geometria. In: VI Seminário de pesquisa em educação matemática do estado do Rio de Janeiro, n. 6, 2008, Rio de Janeiro. Atas. Rio de Janeiro: UNIRIO; 2008. p. 03

BRASIL. Lei n. 9.394, de 20 de dezembro de 1996. Estabelece as diretrizes e bases da educação nacional. Diário Oficial da União, Brasília, 20.12.1996.

BRASIL. Decreto no 5.296, de 2 de dezembro de 2004. Regulamenta as leis federais no 10.048, de 9 de novembro de 2000 e 10.098, de 19 de dezembro de 2000. Diário Oficial da União, Brasília, 2.12. 2004.

BRASIL. Lei no 10.098, de 19 de dezembro de 2000. Estabelece normas gerais e critérios básicos para a promoção da acessibilidade das pessoas portadoras de deficiência ou com mobilidade reduzida. Diário Oficial da União, Brasília, 19.12. 2000.

DEL PRETTE, Zilda Aparecida Pereira; DEL PRETTE, Almir. Habilidades sociais na infância: teoria e prática. Petrópolis: Vozes, 2005.

GÓES, Maria Cecília Rafael de. Os modos de participação do outro nos processos de significação na criança. Temas de Psicologia. Ribeirão Preto, 1, 1993: 1 - 5.

GÓES, Maria Cecília Rafael de. A construção de conhecimentos: examinando o papel do outro nos processos de significação. Temas de Psicologia. Ribeirão Preto, v. 3, n. 2, ago. 1995.

GIL, Marta. Deficiência Visual. Brasília: MEC. Secretaria de Educação a Distância, 2000.

IAPB (AGÊNCIA INTERNACIONAL PARA A PREVENÇÃO DA CEGUEIRA). Cegueira, pobreza e desenvolvimento: o impacto da Visão 2020 no milênio das Nações Unidas metas de desenvolvimento. 2014. Disponível em:

http://www.cbo.com.br/novo/geral/pdf/cegueira_pobreza_e_desenvolvimento.pdf. Acesso em: 06 mai. 2012.

LENT, Roberto, Cem Bilhões de Neurônios. Conceitos fundamentais de neurociência. 
http://dx.doi.org/10.5902/1984686X39149

Atheneu, 2ª edição, São Paulo, 2010.

OLIVEIRA, Luiza. Maria Borges. Cartilha do Censo 2010 - Pessoas com deficiência.

Brasília: Secretaria de Direitos Humanos da Presidência da República (SDH/PR),

Secretaria Nacional de Promoção dos Direitos da Pessoa com Deficiência (SNPD),

Coordenação-Geral do Sistema de Informações sobre a Pessoa com Deficiência, 2012.

ONU (ORGANIZAÇÃO DAS NAÇÕES UNIDAS). Convenção sobre os Direitos das

Pessoas com Deficiência. 2006. Disponível em:

http://www.pessoacomdeficiencia.gov.br/app/sites/default/files/publicacoes/convencaopes soascomdeficiencia.pdf. Acesso em: 04 dez. 2019.

SÁ, Elizabet Dias de; CAMPOS, Izilda Maria de; SILVA, Myriam Beatriz Campolina.

Atendimento Educacional Especializado: Deficiência Visual Brasília: Cromos, 2007.

SKINNER, Burrhus Frederic. Ciência e comportamento humano. Martins Fontes, 2003.

SKINNER, Burrhus Frederic. Tecnologia do ensino. São Paulo: Herder Editora da Universidade São Paulo, 1972.

RABÊLLO, Roberto Sanches. Análise de um experimento de teatro-educação no Instituto de Cegos da Bahia: possibilidades de utilização da linguagem teatral por um grupo de adolescentes. Tese de Doutorado, Faculdade de Educação, Universidade de São Paulo, São Paulo, 2003.

TODOROV, João Claudio; HANNA, Elenice S. Análise do comportamento no Brasil. Psic.: Teor. e Pesq., Brasília, v. 26, n. spe, p. 143-153, 2010.

VYGOTSKY, Lev Semiónovich. A formação social da mente. São Paulo: Martins Fontes, 1998.

VYGOTSKY, Lev Semiónovich. El niño ciego. In: VYGOTSKY, L. S. Obras Escogidas V: Fundamentos de defectología. Madrid: Visor, 1997a.

VYGOTSKY, Lev Semiónovich. La coletividad como factor de desarrollo del niño deficiente. In: VYGOTSKY, L. S. Obras Escogidas V: Fundamentos de defectología. Madrid: Visor, 1997b.

\section{Correspondência}

Carolina Conceição Prado - UDF Centro Universitário, Quadra SEPS, 704/904, Asa Sul, Brasília, Distrito Federal, Brasil.

CEP: $70390-045$ 